\title{
Performance Analysis of Texture Image Classification Using Wavelet Feature
}

\author{
Dolly Choudhary \\ Deptt. Of Computer Sc. \& Engineering \\ Faculty of Engineering \& Tech., MITS Laxmangarh,(India) \\ E-mail: dolly.cse@gmail.com \\ Ajay Kumar Singh \\ Deptt. Of Computer Sc. \& Engineering \\ Faculty of Engineering \& Tech., MITS Laxmangarh,(India) \\ E-mail: ajay.kr.singh07@gmail.com \\ Shamik Tiwari \\ Deptt. Of Computer Sc. \& Engineering \\ Faculty of Engineering \& Tech., MITS Laxmangarh,(India) \\ E-mail: Shamik_tiwari@rediffmail.com \\ Dr. V P Shukla \\ Deptt. Of Mathematics \\ Faculty of Engineering \& Tech. MITS Laxmangarh,(India)
}

\begin{abstract}
This paper compares the performance of various classifiers for multi class image classification. Where the features are extracted by the proposed algorithm in using Haar wavelet coefficient. The wavelet features are extracted from original texture images and corresponding complementary images. As it is really very difficult to decide which classifier would show better performance for multi class image classification. Hence, this work is an analytical study of performance of various classifiers for the single multiclass classification problem. In this work fifteen textures are taken for classification using Feed Forward Neural Network, Naïve Bays Classifier, K-nearest neighbor Classifier and Cascaded Neural Network.
\end{abstract}

Index Terms - Multiclass, Wavelet, Feature Extraction, Neural Network, Naïve Bays, K-NN

\section{INTRODUCTION}

Multi class image classification plays an important role in many computer vision applications such as biomedical image processing, automated visual inspection, content based image retrieval, and remote sensing applications. Image classification algorithms can be designed by finding essential features which have strong discriminating power, and training the classifier to classify the image. Scientists and practitioners have made great efforts in developing advanced classification approaches and techniques for improving classification accuracy [2,3,4,5,6 and 7].
In the past two decades, the wavelet transforms are being applied successfully in various applications, such as feature extraction and classification. Due to their scalespace localization properties, wavelet transforms (and their variants such as wavelet packets) have proven to be an appropriate starting point for classification, especially for texture images $[8,9]$. Also the choice of filters in the wavelet transform plays an important role in extracting the features of texture images $[8,9]$.

In the work [10] describes multi spectral classification of land-sat images using neural networks. [11] Describes the classification of multi spectral remote sensing data using a back propagation neural network. A comparison to conventional supervised classification by using minimal training set in Artificial Neural Network is given in [12]. Remotely sensed data by using Artificial Neural Network based have been classified in [13] on software package. In [14] different types of noise are classified using feed forward neural network.

Naive Bayes $[14,15,16]$ is one of the simplest density estimation methods from which a classification process can be constructed. KNN [17, 18] classification method is a simplest technique conceptually and computationally, but it still provides good classification accuracy. The KNN classification is based on a majority vote of $k$ nearest neighbor classes.

The drawback of multi-layer feed forward networks using error back propagation is that the best number of hidden layers and units varies from task to task and these are determined experimentally. If large number of hidden units are used then the network will learn irrelevant details in the training set. Similarly, if a network is very 
small, it will not be able to learn the training set properly. One approach to automatically determine a good size for a network is to start with a minimal network and then add hidden units and connections as required like the Cascaded Neural Networks. Cascade Feed Forward Neural Networks [19] helps in overcoming this shortcoming by increasing the number of hidden layers dynamically during the learning phase.

This paper is organized into mainly three sections. In the second section classifier used for performance analysis are discussed. Basically the performance is evaluated in four different classifiers as Naïve Bays Classifier, K-Nearest Neighbor (K-NN), Feed Forward Back Propagation Neural Network (BPNN) and Cascaded Neural Network. The third section presents the feature extraction algorithm as well as experimental results,

\section{CLASSIFIERS}

Image classification is also very important area in the field of computer vision, in which algorithms are used to map sets of input, attributes or variables - a feature space $\mathrm{X}$ - to set of labeled classes Y. Such algorithms are called as classifiers. Basically a classifier assigns a pre-defined class label to a sample. Fig 1 shows as simple architecture of the classification system. Any classification system has two stages, training stage and testing stage. Training is the process of defining criteria by which features are recognized. In this process the classifier learns its own classification rules from a training set. In the testing stage, the feature vectors of a query/test image works as input. A classifier decides on the bases of learning model, with its own classification rules, as to which class that feature vector belongs.

\section{A. Naive Bayes Classifier}

This is the simplest density estimation method which is used for classification process $[14,15,16]$. A Naive Bayes classifier categorize patterns to the class $\mathrm{C}$ to which it is most likely to belong based on prior knowledge.

Given a set of feature vectors $=\left\{X_{1}, X_{2}, \ldots, X_{n}\right\}$ and set of classes $\mathrm{C}=\left\{C_{1}, C_{2}, \ldots, C_{m}\right\}$

The corresponding classifier is the equation defined as follows:

$$
\begin{aligned}
& C\left(X_{1}, X_{2}, ., X_{n}\right)= \\
& \operatorname{argmax} p\left(C_{J}\right) \prod_{I=1}^{n} p\left(X_{i} \mid C_{J}\right)
\end{aligned}
$$

\section{B. K-Nearest Neighbor}

KNN [17, 18] classification method is a simplest technique conceptually and computationally, but it still provides good classification accuracy. The KNN classification is based on a majority vote of $k$-nearest neighbor classes. KNN classifier takes only $k$-nearest neighbor classes. So that majority vote is then taken to predict the best-fit class for a point. That means, in a $\mathrm{k}=5$ nearest neighbor classifier, the algorithm will take majority vote of its 5 nearest neighbors. For example, consider Fig 2(a) where $\mathrm{k}=1$, the feature vectors of query image, point $\mathrm{X}$, belongs to class 3 (green circles). If $\mathrm{k}=5$ as in Fig. 2(b) the point $\mathrm{X}$ best-fit in class 1 (blue circles) according to majority vote of the five nearest points.

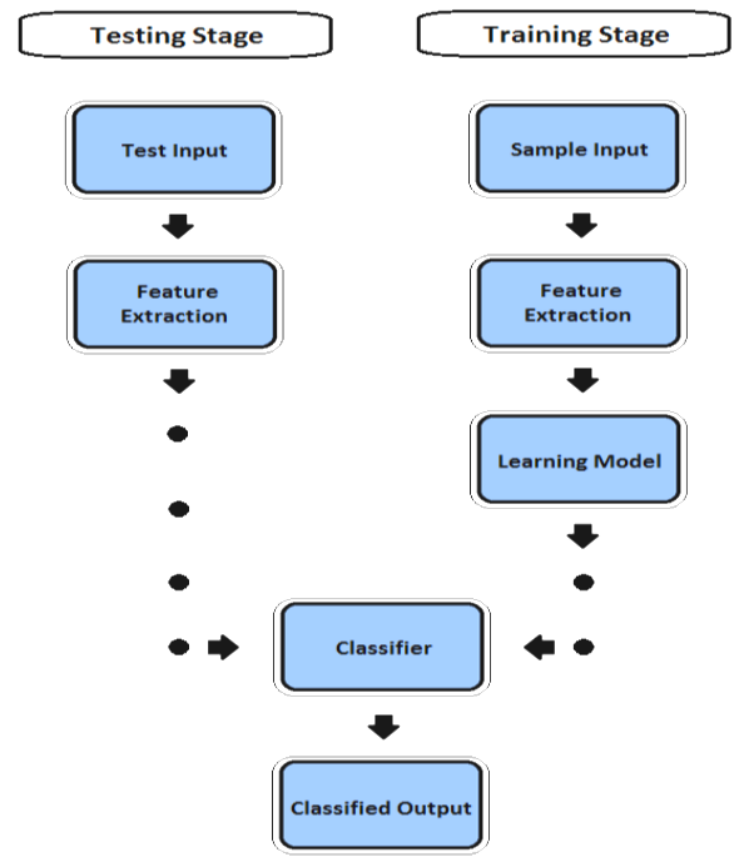

Figure:1. Design of classification system

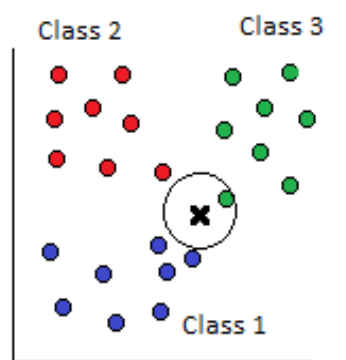

(a) 1-NN Classifier

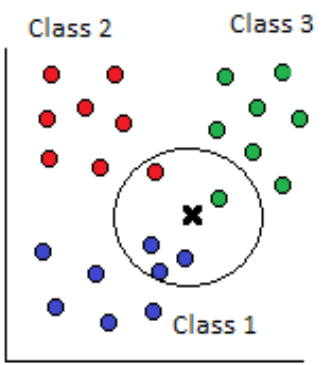

(b) 5-NN Classifier
Figure 2: $k$-Nearest Neighbor classification

The Euclidean distance is used for measuring the distance between the test point and cases from the example classes. The Euclidean distance between two points, $r$ and $s$, is the length of the line segment $r$. Cartesian coordinates if $r=\left(r_{1}, r_{2}, \ldots r_{n}\right)$ and $s=$ $\left(\mathrm{s}_{1}, \mathrm{~s}_{2}, \ldots . \mathrm{s}_{\mathrm{n}},\right)$ are two points in Euclidean $n$-space, then the distance from $r$ to $s$ is given by:

$$
\begin{aligned}
d(r, s) & =\sqrt{\left(\mathrm{r}_{1}-\mathrm{s}_{1}\right)^{2}+\left(\mathrm{r}_{2}-\mathrm{s}_{2}\right)^{2}+\cdots+\left(\mathrm{r}_{\mathrm{n}}-\mathrm{s}_{\mathrm{n}}\right)^{2}} \\
& =\sqrt{\sum_{i=1}^{n}\left(\mathrm{r}_{\mathrm{i}}-\mathrm{s}_{\mathrm{i}}\right)^{2}}
\end{aligned}
$$

In image classification, Cheng et al. [20] used KNN classifier for 20 categories: firstly, images are segmented based on color and texture features. Yanai [21] classified color features into 50 conceptual categories using $\mathrm{KNN}$ classifier. Vogel et al. [22] used a KNN classifier to assign concept keywords to the different area of an image. 


\section{Feed Forward BPNN}

Back propagation is a multi-layer feed forward, supervised learning network based on gradient descent learning rule. This BPNN provides a computationally efficient method for changing the weights in feed forward network, with differentiable activation function units, to learn a training set of input-output data. Being a gradient descent method it minimizes the total squared error of the output computed by the net. The aim is to train the network to achieve a balance between the ability to respond correctly to the input patterns that are used for training and the ability to provide good response to the input that are similar. A typical back propagation network of input layer, one hidden layer and output layer is shown in fig. 3 .

The steps in the BPN training algorithm are:

Step 1: Initialize the weights.

Step 2: While stopping condition is false, execute step 3 to 10 .

Step 3: For each training pair x:t, do steps 4 to 9.

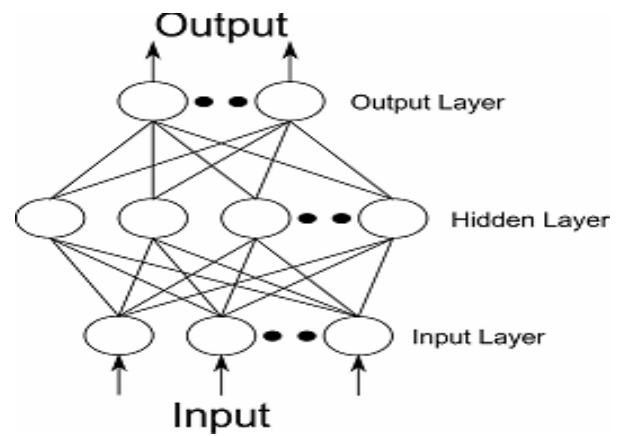

Fig 3: Feed Forward BPN

Step 4: Each input unit $X i, i=1,2, \ldots, n$ receives the input signal, $x_{i}$ and broadcasts it to the next layer.

Step 5: For each hidden layer neuron denoted as

$$
\begin{aligned}
& Z_{j}, \quad j=1,2, \ldots, p . \\
& \mathrm{z}_{\mathrm{inj}}=\mathrm{v}_{\mathrm{oj}}+\sum_{\mathrm{i}} \mathrm{x}_{\mathrm{i}} \mathrm{v}_{\mathrm{ij}} \\
& \mathrm{z}_{\mathrm{j}}=\mathrm{f}\left(\mathrm{z}_{\mathrm{inj}}\right)
\end{aligned}
$$

Broadcast $z_{j}$ to the next layer. Where $\mathrm{v}_{\mathrm{oj}}$ is the bias on $\mathrm{j}^{\text {th }}$ hidden unit.

Step 6: For each output neuron $Y_{k}, k=1,2, \ldots . m$

$$
\begin{aligned}
& \mathrm{y}_{\text {ink }}=\mathrm{w}_{\mathrm{ok}}+\sum_{\mathrm{j}} \mathrm{z}_{\mathrm{j}} \mathrm{w}_{\mathrm{jk}} \\
& \mathrm{y}_{\mathrm{k}}=\mathrm{f}\left(\mathrm{y}_{\text {ink }}\right)
\end{aligned}
$$

Step 7: Compute $\delta_{k}$ for each output neuron, $Y_{k}$

$$
\begin{aligned}
& \delta_{\mathrm{k}}=\left(\mathrm{t}_{\mathrm{k}}-\mathrm{y}_{\mathrm{k}}\right) \mathrm{f}^{\prime}\left(\mathrm{y}_{\mathrm{ink}}\right) \\
& \Delta \mathrm{w}_{\mathrm{jk}}=\alpha \delta_{\mathrm{k}} \mathrm{z}_{\mathrm{j}} \\
& \Delta \mathrm{w}_{\mathrm{ok}}=\alpha \delta_{\mathrm{k}} \quad \text { sin ce } \mathrm{z}_{0}=1
\end{aligned}
$$

Where $\delta_{k}$ is the portion of error correction weight adjustment for $w_{j k}$ i.e. due to an error at the output unit $y_{k}$, which is back propagated to the hidden unit that feed it into the unit $\mathrm{y}_{\mathrm{k}}$ and $\alpha$ is learning rate.

Step 8: For each hidden neuron

$$
\begin{aligned}
& \delta_{\text {inj }}=\sum_{\mathrm{k}=1}^{\mathrm{m}} \delta_{\mathrm{k}} \mathrm{W}_{\mathrm{jk}} \quad \mathrm{j}=1,2, \ldots . . \mathrm{p} \\
& \delta_{\mathrm{j}}=\delta_{\text {inj }} \mathrm{f}^{\prime}\left(\mathrm{z}_{\mathrm{inj}}\right) \\
& \Delta \mathrm{v}_{\mathrm{ij}}=\alpha \delta_{\mathrm{j}} \mathrm{x}_{\mathrm{i}} \\
& \Delta \mathrm{v}_{\mathrm{oj}}=\alpha \delta_{\mathrm{j}}
\end{aligned}
$$

Where $\delta_{j}$ is the portion of error correction weight adjustment for $v_{i j}$ i.e. due to the back propagation of error to the hidden unit $\mathrm{z}_{\mathrm{j}}$

Step 9: Update weights.

$$
\begin{aligned}
& \mathrm{w}_{\mathrm{jk}}(\text { new })=\mathrm{w}_{\mathrm{jk}}(\text { old })+\Delta \mathrm{w}_{\mathrm{jk}} \\
& \mathrm{v}_{\mathrm{ij}}(\text { new })=\mathrm{v}_{\mathrm{ij}}(\text { old })+\Delta \mathrm{v}_{\mathrm{ij}}
\end{aligned}
$$

Step 10: Test for stopping condition.

\section{Cascaded Neural Network}

Cascaded Forward neural network system is similar to feed-forward networks, but include a weight connection from the input to each layer and from each layer to the successive layers. This also is similar to feed forward back propagation neural network in using the back propagation algorithm for weights updating, but the main symptom of this network is that each layer of neurons related to all previous layer of neurons [23].

\section{RELATED WORK}

This work is extension of the work [1] where the texture images of fifteen categories are classified using feed forward back propagation neural network. The performance of the system [1] is compared under four different classifier namely Naïve Bays, Cascaded Neural Network, K-Nearest Neighbor and Feed Forward Neural Network. Here the features are extracted from the texture images and these are applied to each of the classifier to train. Then features of the query images are extracted and applied to each classifier to test.

\section{A. Computation of Feature}

To assess the capability of wavelet feature based classification of images we have taken the texture images as shown in the fig. 4 from the database available by the University of Southern California's Signal and Image Processing Institute Volume 1[24]. Features are extracted 
from the cumulative histogram of various combinations of the Haar wavelet coefficients of the original and complemented image [1]. This algorithm produces a vector of 384 descriptors. Every gray scale image is resized to $256 \times 256$, then it is divided into 64 blocks.
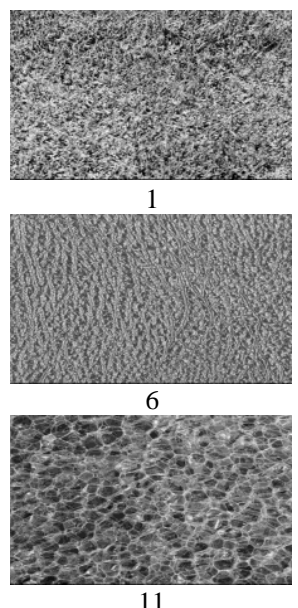

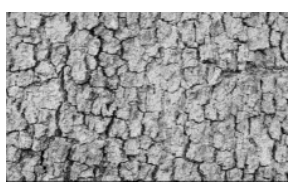

2

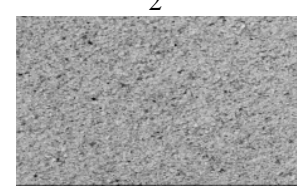

7

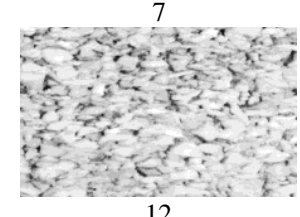

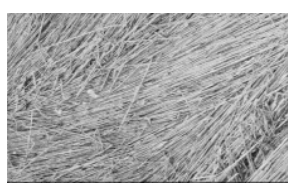
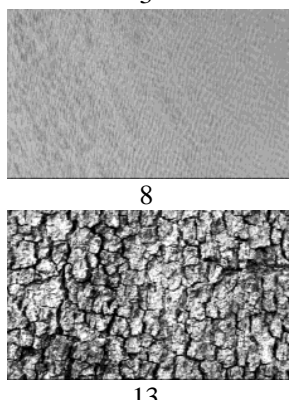

Then feature extraction algorithm [1] is applied to each of the block to create a feature database. Eight feature vectors of each image is used to learn the classifier, remaining are used to test.

Figure.4: Texture Image from Brodatz album

Table I. Performance Evaluation

\begin{tabular}{|c|c|c|c|c|c|}
\hline $\begin{array}{c}\text { S.No } \\
\text {. }\end{array}$ & $\begin{array}{l}\text { Texture } \\
\text { Image }\end{array}$ & $\begin{array}{l}\text { Naïve } \\
\text { Bays }\end{array}$ & $\begin{array}{l}\text { Feed } \\
\text { Forward } \\
\text { BPNN }\end{array}$ & $\begin{array}{c}\text { K- } \\
\text { Nearest } \\
\text { Neighbor }\end{array}$ & $\begin{array}{c}\text { Cascaded } \\
\text { Forward } \\
\text { NN }\end{array}$ \\
\hline 1 & $\begin{array}{l}\text { Grass } \\
\text { (D9) }\end{array}$ & 82.81 & 91.56 & 75.5 & 89.25 \\
\hline 2 & $\begin{array}{c}\text { Bark } \\
\text { (D12) }\end{array}$ & 70.31 & 92.25 & 61 & 75.6 \\
\hline 3 & $\begin{array}{l}\text { Straw } \\
\text { (D15) }\end{array}$ & 53.12 & 82.12 & 61 & 74.23 \\
\hline 4 & $\begin{array}{c}\text { Herring } \\
\text { bone } \\
\text { weave } \\
\text { (D15) } \\
\end{array}$ & 71.89 & 86.02 & 79.7 & 91.29 \\
\hline 5 & $\begin{array}{l}\text { Woolen } \\
\text { cloth } \\
\text { (D19) }\end{array}$ & 53.12 & 95.6 & 68.6 & 83.54 \\
\hline 6 & $\begin{array}{l}\text { Pressed } \\
\text { calf } \\
\text { leather } \\
\text { (D24) }\end{array}$ & 98.44 & 100 & 96.9 & 97.51 \\
\hline 7 & $\begin{array}{c}\text { Beach } \\
\text { sand } \\
\text { (D29) }\end{array}$ & 60 & 85.48 & 74.06 & 80.52 \\
\hline 8 & $\begin{array}{l}\text { Water } \\
\text { (D38) }\end{array}$ & 96.87 & 100 & 98.5 & 94.3 \\
\hline 9 & $\begin{array}{l}\text { Wood } \\
\text { grain } \\
\text { (D68) }\end{array}$ & 55.29 & 93.54 & 82.9 & 70.48 \\
\hline 10 & $\begin{array}{l}\text { Raffia } \\
\text { (D84) }\end{array}$ & 84.37 & 96.8 & 100 & 93.6 \\
\hline 11 & $\begin{array}{l}\text { Plastic } \\
\text { bubbles( } \\
\text { D112) }\end{array}$ & 85.93 & 86.4 & 80 & 88.3 \\
\hline 12 & Gravel & 92.18 & 99.06 & 95.31 & 87.85 \\
\hline 13 & $\begin{array}{c}\text { Field } \\
\text { Stone } \\
\end{array}$ & 75 & 85.25 & 70.31 & 73.5 \\
\hline 14 & $\begin{array}{c}\text { Brick } \\
\text { wall }\end{array}$ & 63.25 & 83.27 & 61.5 & 79.45 \\
\hline 15 & $\begin{array}{l}\text { Pigskin } \\
\text { (D92 } \\
\text { H.E.) } \\
\end{array}$ & 61 & 91.56 & 84.37 & 83.54 \\
\hline
\end{tabular}

Copyright @ 2013 MECS
Step 1:Read the RGB image $f(x, y, z)$

Step 2:Convert the image to gray scale image $f(x, y)$.

Step 3:Compute the Haar wavelet coefficients of step2 image, which returns four matrices A, $\mathrm{H}, \mathrm{V}, \mathrm{D}$ corresponding to approximations, horizontal, vertical \& diagonal coefficients of image.

Step 4:For each pair of coefficients $(\mathrm{A}, \mathrm{H}),(\mathrm{A}, \mathrm{V})$, $(\mathrm{A}, \mathrm{D})$ and $(\mathrm{A}-\mathrm{abs}(\mathrm{V}-\mathrm{H}-\mathrm{D}))$ repeat the step5 to step8.

Suppose first matrix in pair is $\mathrm{X} \&$ second is $\mathrm{Y}$ and get size of matrix is $[\mathrm{M}, \mathrm{N}]$.

Step 5: For $\mathrm{I}=1$ to 8 repeat the step 6 . Where I represents the 8 neighbors in each direction of any point as shown in fig. 2 .

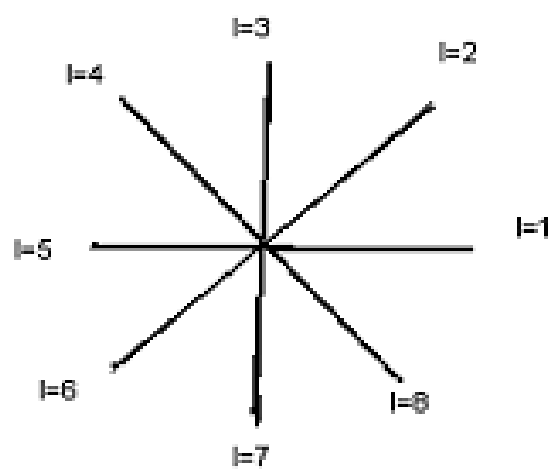

Figure 5: 8 neighbors of any point

Step 6: Repeat for $\mathrm{J}=1$ to $\mathrm{M}$

Repeat for $\mathrm{K}=1$ to $\mathrm{N}$

$\mathrm{d}=\max (\min (\mathrm{X}(\mathrm{J}, \mathrm{K}), \mathrm{Y}(\mathrm{I})), \min (\mathrm{Y}(\mathrm{J}, \mathrm{K}), \mathrm{X}(\mathrm{I})))$ 
if $\mathrm{d}=\min (\mathrm{X}(\mathrm{J}, \mathrm{K}))$

Set $\mathrm{H} 1(\mathrm{I})=\mathrm{X}(\mathrm{J}, \mathrm{K})$

Else

Set $\mathrm{H} 2(\mathrm{I})=\mathrm{Y}(\mathrm{J}, \mathrm{K})$

End

End

Step 7:For $\mathrm{I}=1$ to 8 cumulative histogram of $\mathrm{H} 1 \&$ $\mathrm{H} 2$ is found shown in the fig.

Step 8:For each cumulative histogram correlation coefficient, mean and standard deviation features are computed.

Step 9:Repeat step3 to step 8 for complement image of $f(x, y)$ also.

Step 10:Arrange the features in a matrix.

\section{B. Experimental Result and Discussion}

The classifiers are tested with the texture block of size 16x16. The experimental results of the proposed algorithm [1] of different texture images are compared in the Table.1, which shows the percentage classification rate for different image classes. The analysis of the experimental result shows that, in general, classification accuracy $73.57 \%$ is achieved by Naïve Bays classifier, $91.26 \%$ is achieved by Feed Forward Neural Network, $79.31 \%$ is achieved by KNearest Neighbor and $84.19 \%$ is achieved by Cascaded forward Neural Network.

Fig. 6 showing experimental results using bar chart, which shows that Feed Forward Neural Network demonstrated the best average recognition rate.

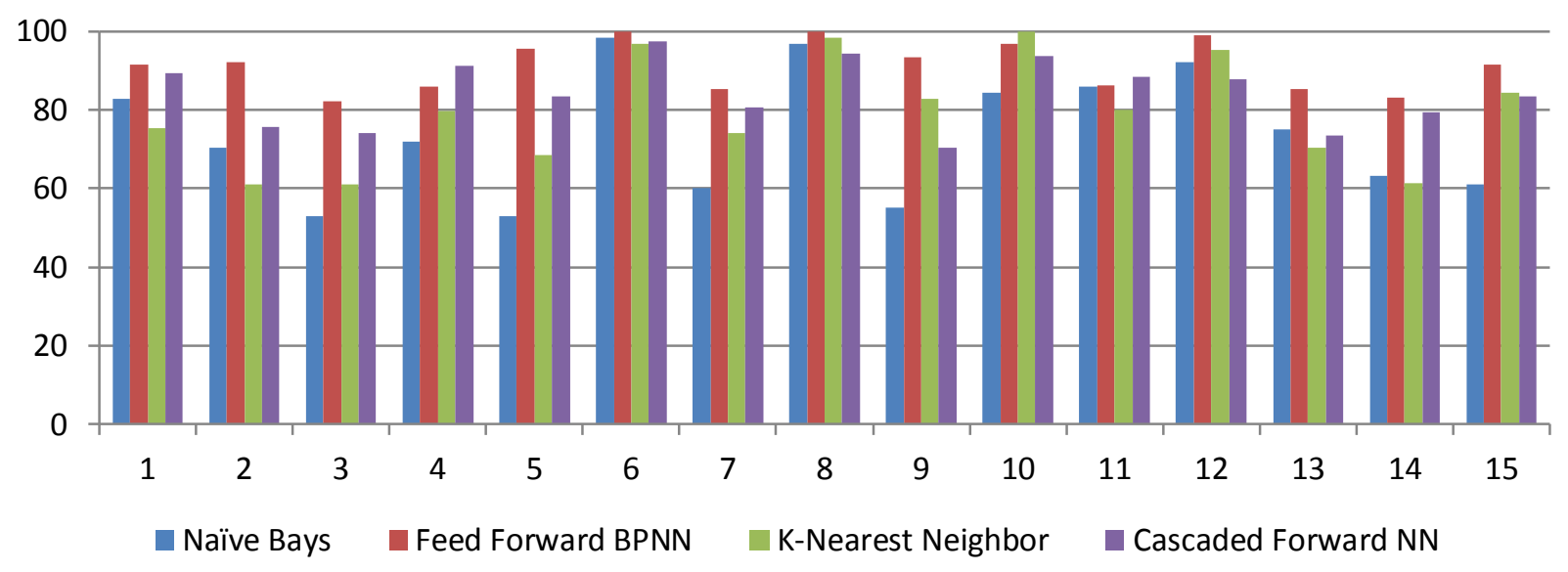

Figure 6: Comparison of recognition rate of classifiers

\section{IV.CONCLUSION}

In this paper a multi class texture images classification, using wavelet based features obtained from image and its complement image is presented. The experimental results are compared under four different classifier namely Naïve Bays, Feed Forward Back Propagation, K-Nearest Neighbor and Cascaded Forward Neural Network. The experimental results demonstrate the efficiency of the various classifiers for multiclass texture image classification. The results are encouraging.

\section{REFERENCES}

[1] Ajay Kumar Singh, Shamik Tiwari, and V P Shukla, "Wavelet based multiclass Image classification using neural network", Proceedings of International Conference on Signal, Image and Video Processing pp.79-83, 2012.

[2] Gong, P. and Howarth, P.J.,’Frequency-based contextual classification and gray-level vector reduction for land-use identification" Photogrammetric Engineering and Remote Sensing, 58, pp. 423-437. 1992.

[3] Kontoes C., Wilkinson G.G., Burrill A., Goffredo, $\mathrm{S}$. and Megier J, "An experimental system for the integration of GIS data in knowledge-based image analysis for remote sensing of agriculture" International Journal of Geographical Information Systems, 7, pp. 247-262, 1993.

[4] Foody G.M., "Approaches for the production and evaluation of fuzzy land cover classification from remotely-sensed data" International Journal of Remote Sensing, 17,pp. 1317-1340 1996.

[5] San miguel-ayanz, J. and Biging, G.S," An iterative classification approach for mapping natural resources from satellite imagery" International Journal of Remote Sensing, 17, pp. 957-982, 1996.

[6] Aplin P., Atkinson P.M. and Curran P.J," Perfield classification of land use using the forthcoming very fine spatial resolution satellite sensors: problems and potential solutions" Advances in Remote Sensing and GIS Analysis, pp. 219-239,1999.

[7] Stuckens J., Coppin P.R. and Bauer, M.E.,'Integrating contextual information with perpixel classification for improved land cover classification" Remote Sensing of Environment, 71, pp. 282-296, 2000. 
[8] Mojsilovic A., Popovic M.V. and D. M. Rackov, "On the selection of an optimal wavelet basis for texture characterization", IEEE Transactions on Image Processing, vol. 9, pp. 2043-2050, December 2000.

[9] M. Unser, "Texture classification and segmentation using wavelets frames", IEEE Transactions on Image Processing, vol. 4, pp. 1549-1560, November 1995.

[10] Bishop H., Schneider, W. Pinz A.J., "Multispectral classification of Landsat -images using Neural Network", IEEE Transactions on Geo Science and Remote Sensing. 30(3), 482-490, 1992.

[11] Heerman.P.D.and Khazenie, "Classification of multi spectral remote sensing data using a back propagation neural network", IEEE trans. Geosci. Remote Sensing, 30(1),81-88,1992.

[12] Hepner.G.F., “Artificial Neural Network classification using minimal training set: comparision to conventional supervised classification" Photogrammetric Engineering and Remote Sensing, 56,469-473,1990.

[13] Mohanty.k.k. and Majumbar. T.J.,"An Artificial Neural Network (ANN) based software package for classification of remotely sensed data", Computers and Geosciences, 81-87, 1996.

[14] Shamik Tiwari, Ajay Kumar Singh and V P Shukla, "Statistical Moments based Noise Classification using Feed Forward Back Propagation Neural Network", International Journal of Computer Applications 18(2):36-40, March 2011.

[15] Rish, I., An empirical study of the naive Bayes classifier, in IJCAI 2001 Workshop on Empirical Methods in Artificial Intelligence, 2001.

[16] Grubinger, M., Analysis and evaluation of visual information systems performance, 2007.

[17] Zhang, H., The optimality of naive Bayes, Proceedings of the 17th International FLAIRS Conference, AAAI Press, 2004.

[18] Zhang, H., Berg, A., Maire, M. and Malik, J., Svm-knn: Discriminative nearest neighbor classification for visual category recognition, in CVPR, 2006.

[19] Duda, R.O., Hart, P.E., and Stork, D.G., Pattern Classification, 2nd Edition, John Wiley. S. E. Fahlman, and C. Lebiere, "The cascadecorrelation learning architecture", in Advances in Neural Information Processing Systems 2, San Mateo, CA: Morgan Kaufmann, 1990,pp. 524-532.

[20] Cheng, Y.C., and Chen, S.Y., Image classification using color, texture and regions, in
Image and Vision Computing, vol. 21 (9), pp. 759-776, 2003.

[21] Yanai, K., Generic image classification using visual knowledge on the Web, in Proceedings of the ACM International Conference on Multimedia, pp. 167-176, Berkeley,2003.

[22] Vogel, J. and Schiele, B., Natural scene retrieval based on a semantic modeling step, in Proceedings of the International Conference on Image and Video Retrieval, pp. 207-215, Dublin, 2004.

[23] R.A. Chayjan., "Modeling of sesame seed dehydration energy requirements by a soft computing”. Australian journal of crop science, vol. 4, no.3, pp.180-184,2010.

[24] Brodatz P., "Textures: A Photographic Album for Artist \& Designers", New York: Dover, New York, 1966.

Dolly Choudhary was born in Lucknow, UP, India, in 1981. She persuaded the B.E in Computer Sc. and Engineering from the Harcourt Butler Technological Institute, Kanpur (UP), India, in 2002 and pursuing M.Tech. from Mody Institute of Technology \& Science, Deemed University Laxmangarh, Raj. India. Her research interests include image processing, security and computer network.

Shamik Tiwari was born in India, in 1980. He received his B.Tech. (Computer Sc. \& Engineering) in 2003, M.Tech. (Computer Sc. \& Engg.) in 2007 from RGPV University Bhopal and Dr. B. R. Ambedkar University Agra respectively. He has joined as a Asst. Prof. in Mody Institute of Technology \& Science, Deemed University Laxmangarh in 2009. Presently, he is pursuing Phd. in Computer Sc. \& Engg. from the MITS Lakshmangarh. He has published over 10 papers in refereed journals and conference proceedings. He is an author of the book "Digital Image Processing" from Dhanpat Rai Publishing (India), His current research interest includes Digital Image Processing, Blur Detection, and their applications in computer vision.

Ajay Kumar Singh was born in India, in 1980. He received his B.E. (Computer Sc. \& Engineering) in 2001, M.Tech. (Information Technology) in 2006 from CCS University Meerut and AAI Deemed University Allahabad respectively. He has joined as a Asst. Prof. in Mody Institute of Technology \& Science, Deemed University Laxmangarh in 2009. Presently, he is pursuing Phd. in Computer Sc. \& Engg. from the MITS Lakshmangarh. He has published over 10 papers in refereed journals and conference proceedings. His current research interest includes Image Processing, Image classification and their applications in computer vision. 